\title{
Microwave Dielectric Relaxation of Alcohols in non polar solutions
}

\author{
T.Ganesh ${ }^{1}$, D.J.S. Anand Karunakaran ${ }^{2}$,P.Udhayageetha ${ }^{1}$, P.Jeevanandham ${ }^{3}$, \\ S.Kumar \\ 1 Post Graduate \& Research Department of Physics Rajah Serfoji Government College, Thanjavur - 613005. \\ Tamil Nadu. \\ 2 Post Graduate \& Research Department of Physics Bishop Heber College, Tiruchirapalli - 620 017,Tamil \\ Nadu \\ 3 Department of Physics, Annamalai University, Annamalai Nagar - 608002, Tamil Nadu
}

\begin{abstract}
The properties of the binary mixtures of 1-propanol and phenol have been studied at constant temperature $303 \mathrm{~K}$ in dilute solutions of benzene using standard standing wave microwave X-band $(9.4 \mathrm{GHz}) \mathrm{J}$ band $(7.4 \mathrm{GHz})$ technique. The values of different dielectric parameters $\varepsilon_{0}, \varepsilon^{\prime}, \varepsilon^{\prime \prime}, \varepsilon_{\infty}$ have been determined for five different mole fractions of 1-propanol and phenol. The values of permittivity and dielectric loss are used to evaluate relaxation time for overall molecular rotation $\left(\tau_{1}\right)$, relaxation time for intermolecular rotations $\left(\tau_{2}\right)$, most probable relaxation time $\left(\tau_{0}\right)$ and dipole moment $(\mu)$ at constant temperature $303 \mathrm{~K}$. The values of relaxation times and dipole moment are found to increases with the mole fraction of 1-propanol, phenol in all binary mixtures. The energy parameter $(\Delta F \tau)$ for dielectric relaxation process of the mixtures is also calculated. It is found that the dielectric relaxation process can be treated as a rate process. The present investigation suggest that existence of both the intermolecular and intramolecular orientation takes place in both binary mixtures.
\end{abstract}

Keywords: Dipolemoment, energy parameters, microwave absorption, relaxation time.

\section{Introduction}

Dielectric relaxation studies of binary mixtures of polar liquids in microwave region provide useful information about self association of solute-solute interaction and solute-solvent type of molecular association [1-7]. Alcohols play an important role in many chemical reactions due to the ability to undergo self-association with manifold internal structure. The interaction study between associated liquid and non-associated in inert media gives valuable information about solute-solute and solute-solvent interaction [8]. 1-propanol is used as a safest antiseptic compound and is also used in the manufacture of insecticides. It is very effective against a broad spectrum of microorganisms including bacteria, fungi, and virus such as HIV, hepatitis-B etc. Dielectric relaxation studies on a variety of mixtures of hydrogen bonded liquids have been performed at microwave frequencies by various researches over a decade. Strong alcohols like 1-propanol and phenol are strongly associative in liquid state and undergo hydrogen bonding with binary solvents which have wider applications. The experimental work concerned with the dielectric relaxation process in the binary mixture of the above two compounds is carried out and molecular association in the different concentration of 1-propanol in the binary mixtures is tried to understand during present course of work.

Phenols are strongly associative in liquid state and undergo hydrogen bonding with many solvents Magee and Walker [9] investigated phenol in number of non polar solvents and found that even at the lowest concentration the relaxation time of alcohol is lengthened by intramolecular association due to either solutesolute or hydrogen bonding of phenol to the $\pi$ electron cloud of solvent or both factors. During last several years, investigations of dielectric relaxation phenomena have provided an important approach to explore the structural behavior of complex organic polar molecules in non-polar solvents. To study the structural behavior of molecules, it is necessary to determine various dielectric parameters which are related with inter and intramolecular association and internal rotation with temperature variation. Recently, dielectric behavior of mixture of different industrial and biological useful polar solvent molecules under varying conditions of compositions has evoked. Considerable interest[10-12] because it helps in formulating adequate models of liquid relaxation and obtaining information about the relaxation process in a polar mixture. The relaxation studies of non-polar solvents provide valuable information about solute-solute and solute solvent interaction [13-15]. Several researchers have studied dilute solutions of non-polar solvents and observed interesting abrupt behavior due to formation of complexes in the mixture of polar molecules [16-18]. In the present investigation the dielectric properties of binary mixtures of 1-propanol and phenol at different concentrations and constant temperature $303 \mathrm{k}$ in dilute solutions of benzene have been carried out and results are reported. 


\section{Experimental Details}

Benzene was dried by refluxing over freshly cut sodium metal for 6-8 hour and distilled through a long vertical fractioning column and middle fraction of the distilled benzene was used. 1-propanol used in these investigations where purchased AR grade from Merck India Ltd., AR grade phenol is used without further purification. The static permittivity $\left(\varepsilon_{0}\right)$ is measured by using a Dipolemeter DM01 supplied by weissenchanijiftlich technische Werkatatter, Germany operated at frequency of $2 \mathrm{MH}_{\mathrm{Z}}$ The refractive indices of the solutions are obtained by abbe's refractometer which in turn give the optical permittivity [19] $\left(\varepsilon_{\infty}=\mathrm{nD}^{2}\right)$ and the results are obtained at a constant temperature $303 \mathrm{~K}$. The densities of the liquids and their mixtures were determined using a specific gravity bottle of capacity $5 \mathrm{~cm}^{3}$. The viscosity of the solution at constant temperatures at $303 \mathrm{~K}$ were measured with Oswald's viscometer. The X band and J band microwave was used to measure wavelength in the dielectric medium and voltage standing wave ratio (VSWR) using a short circuiting plunger. The setup was tuned at microwave frequency $9.4 \mathrm{GH}_{\mathrm{Z}}, 7.4 \mathrm{GH}_{\mathrm{Z}}$.

The energy parameters for the binary mixture have been calculated from the knowledge of their dielectric parameters viz. static permittivity $\left(\varepsilon_{0}\right)$, dielectric constant $\left(\varepsilon^{\prime}\right)$, dielectric loss factor $\left(\varepsilon^{\prime \prime}\right)$ and optical permittivity $\left(\varepsilon_{\infty}\right)$. From the experimental studies, it is found that the dielectric relaxation process depends on the solute-solute association. The excess parameter is evaluated by using Eyring rate equation at constant temperature $303 \mathrm{~K}$. For present investigation double minima method is used for determining the loss factor. The values of $\varepsilon^{\prime}$ and $\varepsilon^{\prime \prime}$ according to this method are given by

$$
\begin{aligned}
& \varepsilon^{\prime}=\left(\frac{\lambda_{0}}{\lambda_{c}}\right)^{2}+\left(\frac{\lambda_{0}}{\lambda_{d}}\right)^{2} \\
& \varepsilon^{\prime \prime}=\frac{2}{\pi}\left(\frac{\lambda_{g}}{\lambda_{d}}\right)^{2}+\left(\frac{\lambda_{0}}{\lambda_{d}}\right)^{2}\left(\frac{d p}{d h}\right)
\end{aligned}
$$

$$
\begin{aligned}
& \text { where } \\
& \qquad \begin{array}{ll}
\rho & =\frac{\sin \theta}{\left(2-\cos ^{2} \theta\right)^{\frac{1}{2}}} \\
\text { and } & \theta=\frac{\pi \Delta x}{\lambda_{g}}
\end{array}
\end{aligned}
$$

Where $\lambda_{\mathrm{c}}$ is the cut-off wave length, $\lambda_{0}$ the free space wave length, $\lambda_{\mathrm{d}}$ the wave length of the dielectric medium, $\lambda_{\mathrm{g}}$ is wave length in the empty wave guide, $\rho$ inverse voltage standing wave ratio, $n$ is the number of minima, $\Delta \mathrm{X}$ is the double minima width in the standing wave patterns. For dilute solutions in non-polar solvents $\varepsilon^{\prime}, \varepsilon^{\prime \prime}$, $\varepsilon_{0}$, and $\varepsilon_{\infty}$ can be expressed as linear functions of concentrations[21-22].

$$
\begin{aligned}
& \varepsilon^{\prime}=\varepsilon^{\prime}+\mathrm{a}^{\prime} \mathrm{W}_{2} \\
& \varepsilon^{\prime \prime}=\mathrm{a}^{\prime \prime} \mathrm{W}_{2} \\
& \varepsilon_{0}=\varepsilon_{10}+\mathrm{a}_{0} \mathrm{~W}_{2} \\
& \varepsilon_{\infty}=\varepsilon_{1 \infty}+\mathrm{a}_{\infty} \mathrm{W}_{2}
\end{aligned}
$$

Here subscript 1 refers to the pure solvent, 2 to the solute, 0 refers to the static (or) low frequency and $\infty$ refers optical frequency. $W_{2}$ is the weight fraction of the solute. The Higasi's [23] parameters $a^{\prime}, a^{\prime \prime}, a_{0}, a_{\infty}$ are the slopes of the above mentioned equations. From the Higasi's parameters dielectric relaxation time $(\tau)$ is evaluated.

$$
\begin{aligned}
& \tau_{0}=\left(\frac{1}{w}\right)\left[\left(\frac{A^{2}+B^{2}}{C^{2}}\right)\right]^{\frac{1}{2}(1-\alpha)} \\
& A=a^{\prime \prime}\left(a_{0}-a_{\infty}\right) \\
& B=\left(a_{0}-a^{\prime}\right)\left(a^{\prime}-a_{\infty}\right)-\left(a^{\prime \prime}\right)^{2} \\
& C=\left(a^{\prime}-a_{\infty}\right)^{2}+\left(a^{\prime \prime}\right)^{2}
\end{aligned}
$$

The values of the dipole moment $(\mu)$ of the solute molecules for all the binary mixtures are calculated by using Higasi's method. 


\section{Result and Discussion}

The dielectric parameters static dielectric constant $\left(\varepsilon_{0}\right)$, dielectric constant at infinite frequency $\left(\varepsilon_{\infty}\right)$, molar polarizability $(\mathrm{P})$, dipole $\operatorname{moment}(\mu)[20]$ and physical parameters viscosity, density of the binary systems are presented in Table-1 \& Table-2 of the 1-proponal and phenol with benzene respectively. The Fig- 2 shows the increase of static dielectric constant with mole fractions of both the binary systems. The dielectric constant, dielectric loss and average relaxation time for different mole fractions of binary mixtures 1-propanol and phenol in dilute solution with benzene for different weight fractions are determined and presented in Table-3 \& Table- 4 respectively. Both the values of $\varepsilon^{\prime}$ and $\varepsilon^{\prime \prime}$ vary linearly with weight fractions of solute in benzene at constant temperature 303K. Fig-1 shows the average relaxation time increases with increase in the mole fractions of the binary mixtures. This may possibly be due to increase in the molar volume. The increase in the values of various relaxation times $\left(\tau_{1}, \tau_{2}\right.$ and $\left.\tau_{0}\right)$ with the concentration of 1-propanol may provide useful indicators for absorption of drugs dissolved in 1-propanol. Since the differences between $\tau_{1}$ and $\tau_{2}$ are significant at all mole fractions, we may expect more than one mechanism in these mixtures. This implies that the dielectric absorption by its molecules is not solely contributed by their rotation as a single unit, but also contains contribution from the intramolecular rotations i.e., it indicates, the existence of an intramolecular relaxation process in addition to the over all relaxation process. From these observations, it may be concluded, that in these mixtures, the intramolecular rotations are dominant as compared to the individual molecular rotations. The average relaxation time $\left(\tau_{0}\right)$ is found increased because the mole fraction of 1-propanol in the binary mixture is increased with increase of relaxation time may be attributed to the increase in effective radius of the rotating unit. In the binary mixture of 1-propanol and phenol, the $\mathrm{CH}_{3}$ group is attached to the same carbon atom to which the $\mathrm{OH}$ groups is attached, this increases the overall size of the molecule and may cause hindrance to the group rotation which may give rise to increases the relaxation time [24-25].

The dipole moment of mixture increases as the mole fraction of 1-proponol in binary mixtures increases Table-1. This is due to shifting of charge centers in the dilute solutions. It may also be realized that increased solute-solute interaction leads to the increase in contribution, because the number of relaxing hydroxyl groups decreases due to association. Probably this effect is partially responsible for the corresponding increases show by the apparent dipole moment. From the measurement of free energy of activation for dielectric relaxation $\Delta \mathrm{F} \tau$ for all system, the $\Delta \mathrm{F} \tau$ is less than excess viscosity $\eta^{\mathrm{E}}$, since relaxation time involves rotational motion where as the viscosity involves both rotational and translational motion.

\section{Acknowledgement}

The authors are gratefully acknowledged the Dr.A.N.Kannappan, Former Professor and Head, Department of Physics Annamalai University, for kindly providing the instrumentation laboratory facility.

\section{References}

[1]. $\quad$ Rana V.A.Vyas A D \& More N M, Indian J Pure \& Appl Phys, 40 (2002) 350.

[2]. Sato T \& Buchner R,J Chem Phys, 118 (2003) 4606.

[3]. Rana V A, Vyas A D \& Mehotra S C, J Mol Liq. 102 (2002) 379.

[4]. Mali C S, Chavan S D, Kanse K S, Kumbharkhane A C \& Mehotra S C, Indian J Pure \& Appl Phys, 4 (2007) 476.

[5]. Sharma V, Thakur N, Sharma D R, negi N S \& Rangara V S, Indian J Pure \& Appl Phys, 5 (2007) 163.

[6]. $\quad$ Madhurima V, Sobhanadri J \& Murthy V R K, Indian J Pure Appl Phys, 42 (2004) 837.

[7]. Prajapati A N, Rana V A \& Vyas A D, Indian J Pure \& Appl Phys, 44 (2006) 620.

[8]. Vyas A D, Rana V A, Bhatnagar S P \& Vashisth V M, Indian J Pure \& Appl Phys, 49 (2011)47.

[9]. Magee M D \& Walker S.J Chem.Phys, 55 (1971) 3068.

[10]. Narwade B.S, Gawali P G, Pande R \& Kalamse G M. J Chem Sci, 117 (2005) 673.

[11]. Manjunath M S \& Sannappa J, Int J Pure \& Appl Phys, 4 (2008) 71.

[12]. Rangra V S \& Sharma D R, Indian J Pure \& Appl Phys, 42 (2004) 921.

[13]. Yaqua M, Ahmed S S \& Hussainb A, Pak J Sci Ind Res, 49 (2006) 225

[14]. Kolling O B. Transactions of the Kansas Academy of Science, 82 (1979) 218

[15]. Kumar R, Chaudhary R K \& Rangra V.S, Indian J Pure \& Appl Phys, 49 (2011) 42

[16]. $\quad$ Singh P J \& Sharma K S, Pramana - Journal of Physics, 46 (1996) 259.

[17]. Kalaivani T \& Krishnan S, Indian J Pure \& Appl Phys, 47 (2009) 880.

[18]. Mohan T M. Sastry S S \& Murthy V R K, Indian J Pure \& Appl Phys, 48 (2010) 668

[19]. Aggarval C, Arya R, GandhiJM \& Sisodia M L, J mol.Liq, 44 (1990) 161.

[20]. Bhatnagar, Indian J Pure \& Appl Phys 49 (2011) 401.

[21]. Franklin, A.D, Hesfton W.H, Henneley E.J \& Smyth C.P, J. Amer. Chem. Soc., 72(1950) 3447.

[22]. Higasi K, Bull. Chem. Soc. Japan, 39(1996) 2157.

[23]. Higasi K, Koga Y\&Nagamure M, Bull. Chem. Soc. Japan, 44(1971) 988.

[24]. Madhu Mohan T, Sreehari Sastry S, Murthy V R K, Indian J Pure \& Appl Phys.,48(2010)668.

[25]. RituJain, Nidhi Bhargava,Sharma K.S, Bhatnagar D, Indian J Pure \& Appl Phys.,49(2011401 
Table 1

Dielectric parameters with various mole fractions of 1-propanal at 303K.

\begin{tabular}{|c|c|c|c|c|c|c|c|c|}
\hline $\begin{array}{c}\mathbf{X}_{2} \\
\text { (Mole } \\
\text { fraction) }\end{array}$ & $\begin{array}{c}\text { Density } \\
\rho_{12} \\
\mathbf{x 1 0}^{3} \\
\mathbf{k g} / \mathbf{m}^{3}\end{array}$ & $\begin{array}{c}\text { Molar } \\
\text { volum } \\
\text { e } \\
\varphi_{12}\end{array}$ & $\begin{array}{c}\varepsilon_{0} \\
(2 \mathrm{MHz} \\
)\end{array}$ & $\begin{array}{c}\boldsymbol{\varepsilon}_{\infty} \\
\left(\mathbf{n}_{\mathbf{D}}\right)^{2}\end{array}$ & $\begin{array}{c}\text { Viscosity } \\
\eta_{12} \\
\mathbf{x 1 0}^{-3} \\
\mathbf{N S M}^{-2}\end{array}$ & $\begin{array}{c}\text { Molar } \\
\text { polariz } \\
\text { ability } \\
\mathbf{P}_{12}\end{array}$ & $\begin{array}{c}\text { Dipole } \\
\text { moment } \\
\text { Higasi's } \\
\text { method } \\
\mu_{\mathrm{ab}}(\mathrm{D})\end{array}$ & $\begin{array}{c}\eta^{\mathrm{E}} \times \mathbf{1 0}^{-3} \\
\mathrm{NSM}^{-2}\end{array}$ \\
\hline 0.02 & 0.864 & 78.68 & 2.385 & 2.223 & 0.750 & 24.847 & 2.674 & 0.121 \\
\hline 0.04 & 0.864 & 78.67 & 2.388 & 2.224 & 0.753 & 24.891 & 2.712 & 0.111 \\
\hline 0.06 & 0.865 & 78.64 & 2.391 & 2.227 & 0.759 & 24.905 & 3.021 & 0.109 \\
\hline 0.08 & 0.865 & 78.61 & 2.407 & 2.230 & 0.763 & 25.100 & 3.373 & 0.104 \\
\hline 0.10 & 0.866 & 78.54 & 2.412 & 2.233 & 0.771 & 25.132 & 3.981 & 0.098 \\
\hline
\end{tabular}

Table 2

Dielectric parameters with various mole fractions of phenol at 303K.

\begin{tabular}{|c|c|c|c|c|c|c|c|c|}
\hline $\begin{array}{c}\mathbf{X}_{2} \\
\text { (Mole } \\
\text { fraction) }\end{array}$ & $\begin{array}{c}\text { Density } \\
\rho_{12} \\
\mathbf{x 1 0}^{3} \\
\mathrm{~kg} / \mathrm{m}^{3}\end{array}$ & $\begin{array}{c}\text { Molar } \\
\text { volume } \\
\varphi_{12}\end{array}$ & $\begin{array}{c}\varepsilon_{0} \\
(2 \mathrm{MHz})\end{array}$ & $\begin{array}{c}\boldsymbol{\varepsilon}_{\infty} \\
\left(\mathbf{n}_{\mathbf{D}}\right)^{2}\end{array}$ & $\begin{array}{c}\text { Viscosity } \\
\eta_{12} \\
\mathbf{x 1 0}^{-3} \\
\text { NSM }^{-2}\end{array}$ & $\begin{array}{c}\text { Molar } \\
\text { polarizability } \\
\mathbf{P}_{12}\end{array}$ & $\begin{array}{c}\text { Dipole } \\
\text { moment } \\
\text { Higasi } \\
\text { method } \\
\mu_{\mathrm{ab}}(\mathrm{D})\end{array}$ & $\begin{array}{c}\eta^{\mathrm{E}} \times \mathbf{1 0}^{-3} \\
\mathrm{NSM}^{-2}\end{array}$ \\
\hline 0.02 & 0.8513 & 100.20 & 2.3216 & 2.2410 & 0.791 & 30.641 & 2.238 & 0.1676 \\
\hline 0.04 & 0.8524 & 100.08 & 2.3721 & 2.2425 & 0.786 & 31.405 & 2.309 & 0.1624 \\
\hline 0.06 & 0.8531 & 100.00 & 2.4715 & 2.2455 & 0.784 & 32.906 & 2.958 & 0.1605 \\
\hline 0.08 & 0.8537 & 99.95 & 2.5110 & 2.2470 & 0.783 & 33.473 & 3.023 & 0.1598 \\
\hline 0.10 & 0.8547 & 99.88 & 2.5701 & 2.2485 & 0.781 & 33.449 & 3.162 & 0.1517 \\
\hline
\end{tabular}

Table 3

Dielectric data and activation energies of 1-propanol in benzene system

\begin{tabular}{|c|c|c|c|c|c|c|c|c|}
\hline $\begin{array}{c}\text { X2 } \\
\text { (mole } \\
\text { fraction) }\end{array}$ & $\begin{array}{c}\boldsymbol{\varepsilon}^{\prime} \\
(\mathbf{X})\end{array}$ & $\begin{array}{c}\boldsymbol{\varepsilon}^{\prime} \\
(\mathbf{J})\end{array}$ & $\begin{array}{c}\varepsilon^{\prime \prime} \\
(\mathbf{X})\end{array}$ & $\begin{array}{l}\varepsilon^{\prime \prime} \\
(\mathbf{J})\end{array}$ & $\begin{array}{c}\Delta \mathbf{F} \tau \\
(\mathbf{X}) \\
\mathbf{K J} / \mathbf{m o l e}\end{array}$ & $\begin{array}{c}\Delta \mathbf{F} \tau \\
(\mathbf{J}) \\
\mathbf{K J} / \mathbf{m o l e}\end{array}$ & $\begin{array}{c}\tau_{\mathbf{0}} \\
(\mathbf{X}) \\
\mathbf{p s}\end{array}$ & $\begin{array}{l}\tau_{0} \\
(J) \\
p s\end{array}$ \\
\hline 0.02 & 2.354 & 2.3617 & 0.667 & 0.731 & 14.941 & 14.830 & 59.62 & 57.05 \\
\hline 0.04 & 2.364 & 2.3710 & 0.701 & 0.810 & 15.281 & 14.898 & 68.24 & 58.61 \\
\hline 0.06 & 2.375 & 2.3819 & 0.721 & 0.831 & 15.441 & 15.199 & 72.72 & 66.05 \\
\hline 0.08 & 2.387 & 2.3929 & 0.737 & 0.850 & 15.581 & 15.341 & 76.85 & 69.87 \\
\hline 0.10 & 2.396 & 2.4021 & 0.747 & 0.892 & 16.475 & 16.459 & 109.6 & 108.92 \\
\hline
\end{tabular}

Table 4

Dielectric data and activation energies of phenol in benzene system

\begin{tabular}{|c|c|c|c|c|c|c|c|c|}
\hline $\begin{array}{c}\mathbf{X} 2 \\
(\mathbf{m o l e} \\
\text { fraction) }\end{array}$ & $\begin{array}{c}\mathbf{\varepsilon}^{\prime} \\
(\mathbf{X})\end{array}$ & $\begin{array}{c}\mathbf{\varepsilon}^{\prime} \\
(\mathbf{J})\end{array}$ & $\begin{array}{c}\mathbf{\varepsilon}^{\prime \prime} \\
(\mathbf{X})\end{array}$ & $\begin{array}{c}\boldsymbol{\varepsilon}^{\prime \prime} \\
(\mathbf{J})\end{array}$ & $\begin{array}{c}\Delta \mathbf{F} \boldsymbol{\tau} \\
(\mathbf{X}) \\
\mathbf{K J} / \mathbf{m o l e}\end{array}$ & $\begin{array}{c}\Delta \mathbf{F} \boldsymbol{c} \\
(\mathbf{J}) \\
\mathbf{K J} / \mathbf{m o l e}\end{array}$ & $\begin{array}{c}\boldsymbol{\tau}_{\mathbf{0}} \\
(\mathbf{X}) \\
\mathbf{p s}\end{array}$ & $\begin{array}{c}\boldsymbol{\tau}_{\mathbf{0}} \\
(\mathbf{J}) \\
\mathbf{p s}\end{array}$ \\
\hline 0.02 & 2.2544 & 2.2982 & 0.2062 & 0.3774 & 7.8122 & 0.1642 & 03.52 & 14.26 \\
\hline 0.04 & 2.2538 & 2.3171 & 0.2340 & 0.3920 & 11.3033 & 0.1691 & 14.07 & 14.40 \\
\hline 0.06 & 2.2714 & 2.3314 & 0.2410 & 0.4079 & 12.0455 & 0.1731 & 18.89 & 20.39 \\
\hline 0.08 & 2.2880 & 2.3562 & 0.2620 & 0.4248 & 14.5669 & 0.1802 & 51.43 & 28.72 \\
\hline 0.10 & 2.3061 & 2.3683 & 0.2855 & 0.4438 & 15.5018 & 0.1873 & 74.47 & 29.67 \\
\hline
\end{tabular}




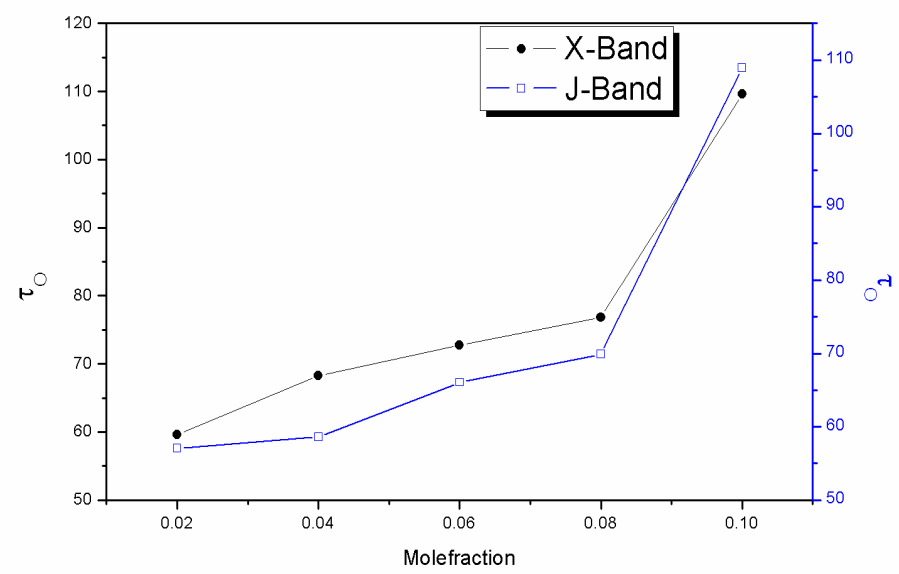

Figure-1 : Molefraction Vs Relaxation time

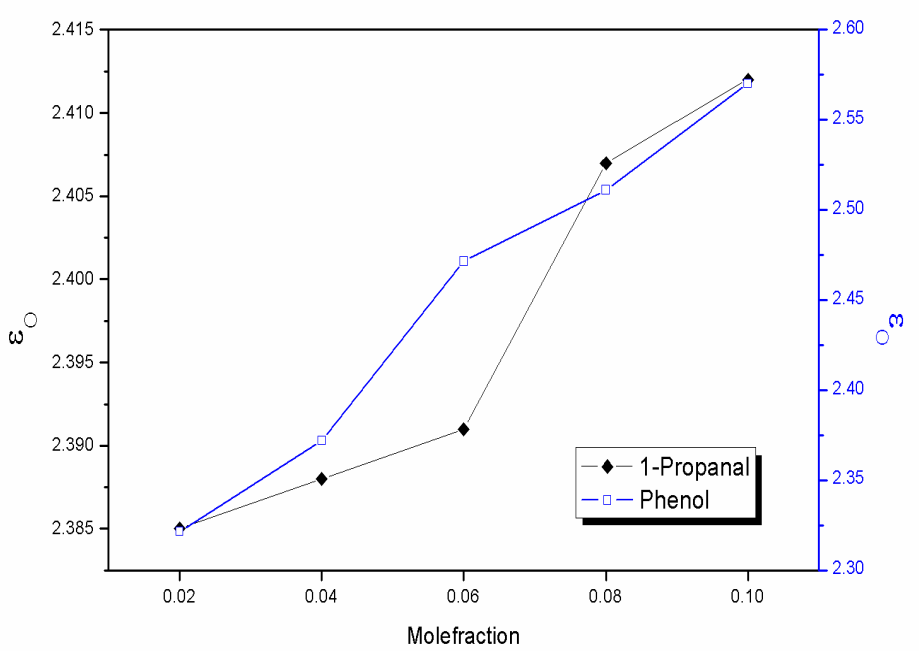

Figure-2 : Molefraction Vs Static Dielectric Constant 